\title{
MELIOSMA MEXICANA (SABIACEAE), UNA ESPECIE NUEVA DE LA SIERRA MADRE ORIENTAL DE MÉXICO
}

\author{
Victor W. SteinMANN \\ Instituto de Ecología, A.C., Centro Regional del Bajío, Apdo. postal 386, \\ 61600 Pátzcuaro, Michoacán, México
}

\begin{abstract}
RESUMEN
Se describe como especie nueva a Meliosma mexicana (Sabiaceae). Es endémica de la Sierra Madre Oriental de México en los estados de Querétaro y Tamaulipas. Crece desde los 800 hasta los $1900 \mathrm{~m}$ de altitud en el bosque mesófilo de montaña y el bosque de pino-encino húmedo. Pertenece al subg. Meliosma sect. Lorenzanea y es morfológicamente parecida a M. dentata, a la cual aparentemente remplaza en el noreste de México. Meliosma mexicana se distingue de $M$. dentata por tener hojas esencialmente enteras, glándulas estipitadas que varían de color rojizo a negruzco, y frutos subglobosos de 0.6 a $0.7(0.8) \mathrm{cm}$ de largo.
\end{abstract}

Palabras clave: Meliosma, México, Sabiaceae, Sierra Madre Oriental.

\begin{abstract}
Meliosma mexicana (Sabiaceae) is described as a new species. It occurs in the Sierra Madre Oriental of Mexico in the states of Querétaro and Tamaulipas, growing primarily in cloud forest and humid pine-oak forest at elevations of 800 to $1900 \mathrm{~m}$. It belongs to subg. Meliosma sect. Lorenzanea. It is most similar to $M$. dentata, which it apparently replaces in northeastern Mexico. Meliosma mexicana is distinguished from M. dentata in having essentially entire leaves, stipitate glandular trichomes that vary from red to blackish, and subglobose fruits 0.6 to $0.7(0.8) \mathrm{cm}$ long.
\end{abstract}

Key words: Meliosma, Mexico, Sabiaceae, Sierra Madre Oriental.

La familia Sabiaceae contiene tres géneros y alrededor de 60 especies (Cronquist, 1981). Meliosma Blume es el único género en México, donde existen unas 11 
especies (Villaseñor, 2004). Entre ellas la más común es Meliosma dentata (Liebm.) Urban, un componente característico de bosque mesófilo de montaña y bosque de pino-encino húmedo. Se distribuye desde el sur de Chihuahua hasta Veracruz y Chiapas; también se ha registrado en Guatemala (Standley y Steyermark, 1949) y Nicaragua (Gentry, 2001). Durante la revisión de Meliosma para el proyecto Flora del Bajío y de regiones adyacentes, se encontraron varias colectas de la Sierra Madre Oriental de México similares a Meliosma dentata pero que difieren en varios aspectos. Ya que estas colectas no coinciden con ninguna de las especies descritas, se propone como especie nueva a:

Meliosma mexicana V.W. Steinm., sp. nov.-TIPO: México, Querétaro, mpio. Jalpan, al SE de San Juan de los Durán, Cañada Las Avispas, \pm abundante a lo largo de la cañada, 1600-1900 m, bosque mesófilo de montaña, 03 abril 1991, H. Díaz y E. Carranza 6551 (holotipo IEB; isotipo MEXU). Fig. 1.

Meliosmae dentatae affinis a qua imprimis differt foliis integerrimis, glandulis stipitatis et fructibus brevioribus.

Árbol perennifolio, hasta de $20 \mathrm{~m}$ de alto; corteza rojiza con lenticelas; ramillas de 2 a $4 \mathrm{~mm}$ de grueso, densamente estrigosas con pelos aciculares de 0.4 a 0.8 $\mathrm{mm}$ de largo, glándulas estipitadas negruzcas a rojizas a menudo presentes; hojas alternas, estípulas ausentes; peciolos de 0.6 a $1.5 \mathrm{~cm}$ de largo, glabros a estrigosos o hirsútulos; láminas simples, elípticas o rara vez obovadas, a veces algo asimétricas, de 6 a 14.5(17.5) cm de largo, de 1.5 a $4.5(6.5) \mathrm{cm}$ de ancho, penninervadas con 5 a 8 nervaduras secundarias, ligeramente broquidódromas, nervación terciaria reticulada, ápice acuminado, base atenuada, margen entero o algo ondulado, rara vez con uno o dos dientes inconspicuos hacia el ápice, glabras excepto la nervadura principal; inflorescencia una panícula terminal hasta de $13 \mathrm{~cm}$ de largo, raquis densamente hírtulo a estrigoso, con glándulas estipitadas negruzcas a rojizas; flores hermafroditas, sobre pedicelos de 0.9 a $1.4 \mathrm{~mm}$ de largo; sépalos 5, libres, ligeramente desiguales, ovados, de 1.3 a $1.7 \mathrm{~mm}$ de largo, de 0.8 a $1.4 \mathrm{~mm}$ de ancho, ápice agudo a obtuso, algo puberulentos y con glándulas estipitadas por fuera rara vez glabras, glabros por dentro, margen ciliado; pétalos 5, desiguales, 3 externos grandes, anchamente ovados a casi orbiculares, de 1.7 a $2.3 \mathrm{~mm}$ de largo, de 2.8 a $3.6 \mathrm{~mm}$ de ancho, blancos, unidos en la base, ápice obtuso, glabros, 2 internos pequeños, situados en la base de los 2 estambres fértiles, bífidos, de 1.1 a $1.3 \mathrm{~mm}$ de largo, de 0.4 a $0.5 \mathrm{~mm}$ de ancho, ligeramente pubescentes; estambres fértiles 2, filamentos angostamente 


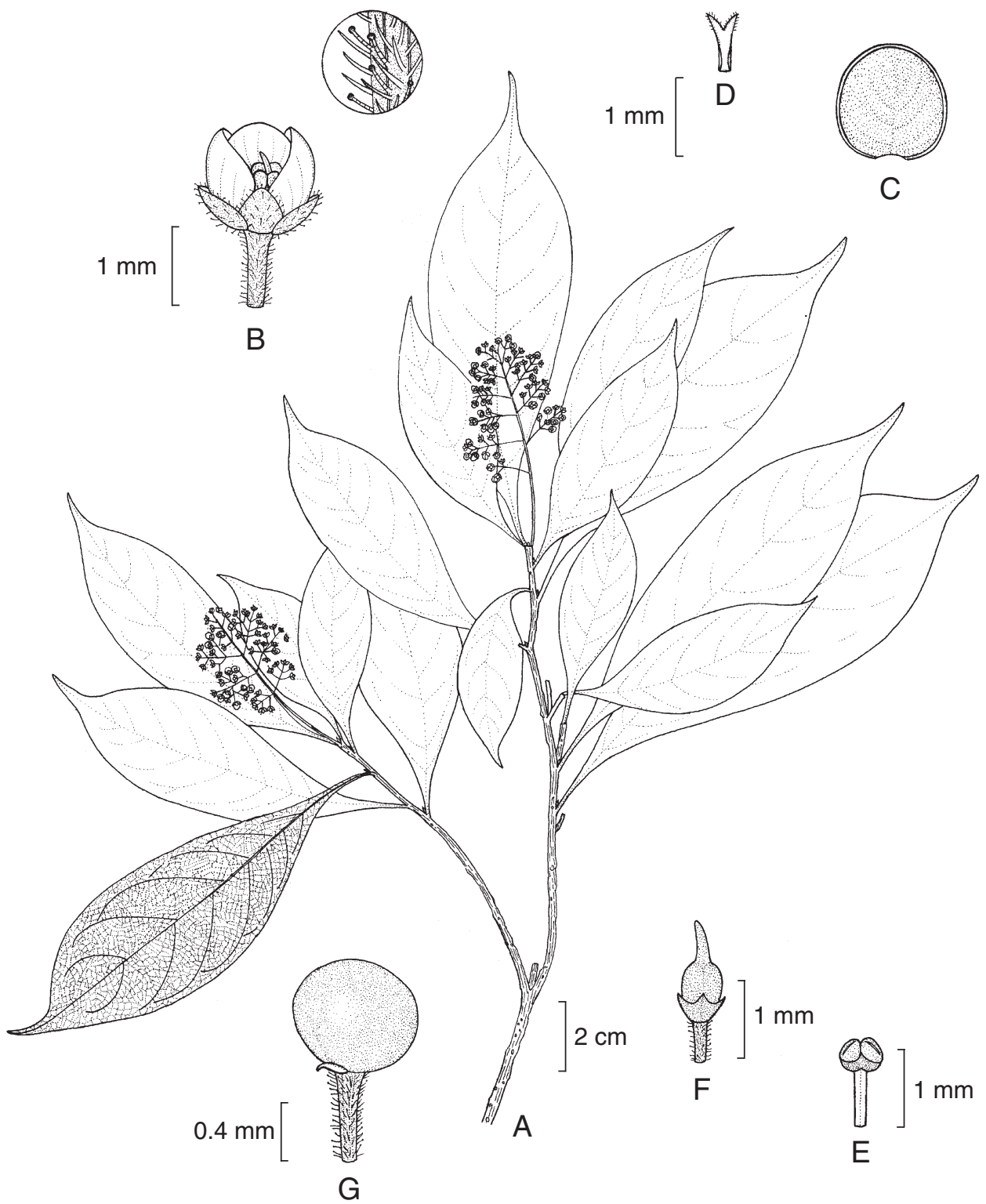

Fig. 1. Meliosma mexicana V.W. Steinm. A. rama con hojas e inflorescencias; B. vista externa de la flor y acercamiento de la pubescencia de los pedicelos; C. pétalo externo; D. pétalo interno; E. estambre; F. gineceo rodeado por el disco; G. fruto. Ilustrado por Rogelio Cárdenas. 
cilíndricos, de 1.1 a $1.6 \mathrm{~mm}$ de largo, glabros, anteras biloculares, de 0.6 a $0.7 \mathrm{~mm}$ de largo, de $1 \mathrm{a} 1.1 \mathrm{~mm}$ de ancho, las tecas separadas por un conectivo engrosado; complejo estaminodial de 1.4 a $1.7 \mathrm{~mm}$ de largo; disco dividido en segmentos angostamente triangulares a subulados; ovario ovoide, glabro, estilo cilíndrico, recto, adelgazándose en la porción distal, de 1.1 a $1.5 \mathrm{~mm}$ de largo, estigma en el ápice del estilo, punctiforme; fruto drupáceo, subgloboso, de 0.6 a $0.7(0.8) \mathrm{cm}$ de largo, glabro, rojizo con el mesocarpo carnoso al madurarse, endocarpo extremadamente duro.

Distribución y habitat. Meliosma mexicana es endémica de la Sierra Madre Oriental en el noreste de México, se conoce solamente de tres colectas del noreste de Querétaro y varias adicionales del sur de Tamaulipas, estas últimas principalmente de los alrededores del Rancho el Cielo en el municipio de Gómez Farías. Es probable que se encuentre también en San Luis Potosí. Crece desde los 800 hasta los 1900 m de altitud en el bosque mesófilo de montaña y el bosque de pino-encino húmedo.

Fenología. Florece en marzo y abril y presenta frutos de junio a octubre. Las flores se registran como muy aromáticas.

Discusión. Según la clasificación subgenérica de van Beusekom (1971), Meliosma mexicana pertenece al subgénero Meliosma sect. Lorenzanea (Liebm.) Beus. Es parecida a $M$. dentata, y aparentemente la remplaza en el noreste de México. Como su nombre sugiere, las hojas de $M$. dentata son claramente aserradas a dentadas; en contraste $M$. mexicana tiene hojas enteras o ligeramente onduladas, rara vez con uno o dos dientes inconspicuos hacia el ápice. Los sépalos, raquis de la inflorescencia, ramillas y hojas de M. mexicana poseen glándulas estipitadas que varían de color rojizo a negruzco, mientras que en $M$. dentata dichas glándulas están ausentes. Meliosma mexicana también se distingue por tener frutos más pequeños (0.6 a $0.7(0.8) \mathrm{cm}$ de largo vs. 0.9 a $1.2(1.4) \mathrm{cm}$ de largo). Además, los frutos maduros de $M$. mexicana siempre son subglobosos y redondeados en la base mientras que los de $M$. dentata frecuentemente son ligeramente obpiriformes y constrictos en la base. Cabe mencionar que mientras M. mexicana parece constante en las características anteriormente mencionadas, rara vez $M$. dentata puede tener hojas esencialmente enteras o frutos redondeados y no constrictos en la base. Por ello, la única característica que las separa invariablemente es la presencia de glándulas estipitadas en $M$. mexicana. 
Paratipos. Querétaro: mpio. Landa, El Naranjo, F. Lorea 691 (IEB); mpio. Jalpan, $\pm 3.5 \mathrm{~km}$ al SE de San Juan de los Durán por el camino a la Cañada de las Avispas, 2127'29" N, 9908'49.2" W, S. Zamudio y L. Hernández 12615 (IEB). Tamaulipas: vicinity of Gómez Farías, J.A. Duke M3525 (MEXU); Rancho del Cielo, arriba de Gómez Farías, A. Gómez-Pompa 2036 (MEXU); mpio. Gómez Farías, Sierra de Guatemala, entre Alta Cima y Rancho del Cielo, F. González-Medrano et al. 4256 (MEXU); mpio. Gómez Farías, camino a Ojo de Agua del Indio, 7 km al W de Rancho del Cielo y $18 \mathrm{~km}$ al W de Gómez Farías, F. González-Medrano et al. 4294 (MEXU); mpio. Gómez Farías, Rancho del Cielo a 11 km de Gómez Farías, F. González-Medrano et al. 7396 (MEXU); ibid., F. González-Medrano et al. 7435 (MEXU); ibid., F. González-Medrano et al. 7440 (MEXU); mpio. Llera, Rancho El Julilo, $15 \mathrm{~km}$ al NW de Gómez Farías, F. González-Medrano et al. 10407 (MEXU); mpio. Gómez Farías, alrededores de Rancho del Cielo, M. Martínez 1753 (IEB); mpio. Gómez Farías, along trail from Rancho del Cielo to Julilo, between Rancho del Cielo Biological Station and "Mine Turn" 6.5 km NW of Gómez Farías, M. Nee \& G. Diggs 24502 (MEXU); mountains W of the Río Sabinas on the rd to Hulilo (Julilo), K. Robertson y D.G. LeDoux 137 (MEXU); Sierra de Guatemala above Gómez Farías, Rancho del Cielo, A.J. Sharp et al. 52048 (MEXU); Rancho del Cielo, 11 km al NW de Gómez Farías, R. Torres C. 3127 y H. Hernández (MEXU).

\section{AGRADECIMIENTOS}

Agradezco a Paul Fryxell, Yocupitzia Ramírez-Amezcua y un revisor anónimo por la revisión crítica del escrito; a los responsables de los herbarios IEB y MEXU por proporcionar especímenes; a Rogelio Cárdenas por el dibujo; así como el apoyo económico recibido del Instituto de Ecología, A.C. (cuenta 902-07), del Consejo Nacional de Ciencia y Tecnología (CONACYT) y de la Comisión Nacional para el Conocimiento y Uso de la Biodiversidad (CONABIO).

\section{LITERATURA CITADA}

Cronquist, A. 1981. An integrated system of classification of flowering plants. Columbia Univ. Press. Nueva York. 1262 pp.

Gentry, A. H. 2001. Sabiaceae In: Stevens, W. D., C. Ulloa Ulloa, A. Pool y O. M. Montiel (eds.). Flora de Nicaragua 3: 2303-2306. 
Standley, P. C. y J. A. Steyermark. 1949. Flora of Guatemala, Sabiaceae. Fieldiana 24(6): 273-275.

van Beusekom, C. F. 1971. Revision of Meliosma (Sabiaceae), section Lorenzanea excepted, living and fossil, geography and phylogeny. Blumea 19: 355-529.

Villaseñor, J. L. 2004. Los géneros de plantas vasculares de la flora de México. Bol. Soc. Bot. Méx. 75: 105-135.

Recibido en septiembre de 2006.

Aceptado en diciembre de 2006. 